\title{
Effect of hypovitaminosis D and its related factors in pregnant women and their newborns
}

\author{
Amrita Sandhu $^{1}$, Ruchira Nautiyal ${ }^{1 *}$, Vinit Mehrotra ${ }^{2}$, Sanober Wasim ${ }^{3}$
}

\begin{abstract}
${ }^{1}$ Department of Obstetrics and Gynecology, ${ }^{2}$ Department of Biochemistry, ${ }^{3}$ Department of Pediatrics, Himalayan Institute of Medical Sciences, Dehradun, Uttarakhand, India
\end{abstract}

Received: 10 January 2019

Accepted: 06 February 2019

\section{*Correspondence:}

Dr. Ruchira Nautiyal,

E-mail: ruchiranautiyal@srhu.edu.in

Copyright: $\odot$ the author(s), publisher and licensee Medip Academy. This is an open-access article distributed under the terms of the Creative Commons Attribution Non-Commercial License, which permits unrestricted non-commercial use, distribution, and reproduction in any medium, provided the original work is properly cited.

\begin{abstract}
Background: Maternal and fetal vitamin D deficiency has nowadays emerged as a frequent morbidity. Adequate vitamin D concentrations during pregnancy are necessary to maintain neonatal calcium homeostasis, bone maturation and mineralization. Objectives of this study were to evaluate serum vitamin D concentration in mothers and its correlation with neonatal cord blood vitamin D at the time of delivery and to study the impact of hypovitaminosis on neonatal anthropometry. Effect of related factors like calcium (Ca), alkaline phosphatase (ALP) and parathyroid hormone (PTH) on maternal vitamin D levels were to be evaluated.

Methods: Cross sectional study was done on a total of 220 healthy uncomplicated antenatal females with singleton pregnancy attending labor room at the time of delivery. Maternal and neonatal cord blood samples were drawn in the delivery room and analyzed. Neonatal anthropometry was recorded. Correlations among various maternal and neonatal factors were studied.

Results: Widespread vitamin D deficiency was observed in expectant subjects and neonates with $70.91 \%$ having deficient levels which were also reflected in newborns (71.82\%). Maternal ALP $(r=-0.5503, p=0.000)$ bears a weak negative correlation $(\mathrm{p}<0.05)$, maternal serum Ca positive correlation $(\mathrm{r}=0.7486, \mathrm{p}=0.000)$ and plasma PTH levels a negative correlation $(r=-2.084, p=0.000)$ with hypovitaminosis. No significant correlation was observed between neonatal anthropometry and vitamin $\mathrm{D}$ levels.

Conclusions: High prevalence of hypovitaminosis was observed among pregnant women and their neonates in this study. A positive linear relationship was seen between maternal and cord blood vitamin D (r 0.974, p 0.0001).
\end{abstract}

Keywords: Alkaline phosphatase, Calcium, Parathyroid hormone, Vitamin D

\section{INTRODUCTION}

Vitamin D is a distinct vitamin as in contrast to other vitamins it can be manufactured endogenously from exposure to sunlight and also can be derived from natural food sources. ${ }^{1}$ It has many classical actions which were first illustrated in the kidneys and bones. A distinguished fact nowadays is that vitamin D, the "sunshine vitamin", is furthermore involved in various non-classical processes and has multiple functions. ${ }^{2}$ It has emerged to play a vital role in the health of mothers and neonates. With extensive research hypovitaminosis $\mathrm{D}$ is seen to be in association with higher risk of hypertensive disorder like pre-eclampsia, gestational diabetes mellitus, reduced fetal bone mineral accumulation, wheezing and respiratory infections in infants. ${ }^{3-6}$

Ante-partum vitamin D status of mother is crucial as $30 \%$ of fetal skeleton is accrued in later gestation and is dependent on maternal vitamin D status. Various studies have concluded that fetal and neonatal vitamin D is closely connected to status of maternal vitamin D. 
Because of outstandingly higher prevalence of vitamin D deficiency, the possible health consequence must not be underestimated. It is seen that incidence of rickets is increasing in developing as well as developed nations (7). Lower concentrations of maternal vitamin D during the prenatal as well as perinatal period can severely affect the role of various other cells and tissues which might lead to an increased possibility of various types of cancers, multiple sclerosis, schizophrenia and insulin-dependent diabetes later in life. .,8 $^{7}$

In a country like India, which is a tropical country and has ample amount of overhead sun throughout the year; it is bewildering to see such a high occurrence of hypovitaminosis D. Various predominant cultural and social rituals in India that prohibit adolescent girls and young women to have a sufficient amount of exposure to sunlight might partly explain this paradox. Pregnancy is unquestionably a very critical phase in a woman's life all through which there is an increase in nutritional requirements of the body.

Also, vitamin D in mothers is related to various health outcomes throughout the duration of pregnancy and neonatal and infant development. Hence, maintenance of sufficient amount of intake and meeting vitamin D requirements throughout the life cannot be stressed enough. ${ }^{9}$

Therefore, the primary aim of this study was to evaluate serum vitamin D concentration in mothers and its correlation with cord blood vitamin D of their new-borns at the time of delivery and to study the impact of vitamin D deficiency on neonatal anthropometry. Further, the effect of related factors like calcium, alkaline phosphatase and parathyroid hormone on maternal serum 25-hydroxyvitamin D levels has also been evaluated.

\section{METHODS}

This study was conducted in the Department of Obstetrics and Gynecology and Department of Pediatrics, Himalayan Institute of Medical Sciences, Swami Ram Nagar, Dehradun over a period of 12 months from May 2017 to April 2018. Subjects were enrolled from the labor room of SRHU campus, Dehradun. A written informed consent was taken in Hindi and English from subjects involved in the study.

\section{Inclusion criteria}

- A total of 220 antenatal females (primigravida or multigravida) with single intrauterine pregnancy presenting to the labor room of Himalayan hospital at the time of delivery and their newborns.

\section{Exclusion criteria}

- Women with multiple gestation,

- History of rheumatoid arthritis,
- Type-I diabetes mellitus,

- Parathyroid/thyroid/ adrenal/ renal or hepatic disease.

- Women on medications influencing the metabolism of calcium, vitamin $\mathrm{D}$ and bones.

The complete history was recorded and clinical examination was carried out according to pre-set case recording form. Necessary blood samples were drawn in the delivery room. Measurement of maternal and neonatal vitamin $\mathrm{D}$ was done by commercially available vitamin $\mathrm{D}$ kit (VIDAS Kit) using enzyme immunoassay method and their correlation was determined. Maternal serum concentration of ALP, calcium and PTH was determined by standard methods (Beckman-Coulter) and their correlation with maternal serum vitamin D levels was done. Neonatal weight, gestational age, length and head circumference was measured at 24 hours of life. Normal range of vitamin $\mathrm{D}$ was taken as $75-250 \mathrm{nmol} / \mathrm{L}$.

Patients were classified into three categories: - vitamin D deficiency $=<25 \mathrm{nmol} / \mathrm{L}$, vitamin $\mathrm{D}$ insufficiency $=25-$ $75 \mathrm{nmol} / \mathrm{L}$, sufficient vitamin $\mathrm{D}=>75 \mathrm{nmol} / \mathrm{L}$. Normal range of ALP was taken as 33-96 IU/L, PTH was taken as $15-65 \mathrm{picogm} / \mathrm{ml}$ and calcium was taken as $8.5-10 \mathrm{mg} / \mathrm{dl}$.

Interpretation and analysis of obtained data was carried out using software SPSS version 22. Data analysis was done with both parametric (paired't' test) and nonparametric (chi-square) tests to ascertain statistical significance.

Spearman correlation was performed based on the ability to detect the relationship between various parameters. $\mathrm{P}<0.05$ was considered statistically significant.

\section{RESULTS}

Majority of the patients $(50.45 \%)$ belonged to the age group of 19- 25 years. Mean age of the patients was $25.75 \pm 3.36$ years.

$70.91 \%$ of the 220 antenatal females had vitamin D deficiency, $19.09 \%$ patients had vitamin D insufficiency and $10 \%$ had sufficient vitamin D levels respectively, as shown in Table 1.

Table 1: Distribution of maternal and neonatal cord blood Vitamin D levels.

\begin{tabular}{|c|c|c|c|}
\hline $\begin{array}{l}\text { Vitamin D } \\
(\mathrm{nmol} / \mathrm{L})\end{array}$ & $\begin{array}{l}<25 \\
\text { (deficient) }\end{array}$ & $\begin{array}{l}\text { 25-75 } \\
\text { (insufficient) }\end{array}$ & $\begin{array}{l}>75 \\
\text { (sufficient) }\end{array}$ \\
\hline $\begin{array}{l}\text { Maternal } \\
\text { (No. of } \\
\text { cases (n: } \\
220 \text { ) }\end{array}$ & $\begin{array}{l}156 \\
(70.91 \%)\end{array}$ & $42(19.09 \%)$ & $22(10.00 \%)$ \\
\hline $\begin{array}{l}\text { Neonatal } \\
\text { (No. of } \\
\text { cases (n: } \\
220 \text { ) }\end{array}$ & $\begin{array}{l}158 \\
(71.82 \%)\end{array}$ & $37(16.82 \%)$ & $25(11.36 \%)$ \\
\hline
\end{tabular}


Neonatal cord blood was deficient in vitamin $D$ in $71.82 \%$ of the neonates. Insufficient vitamin D levels were seen in $16.82 \%$ of the neonates.

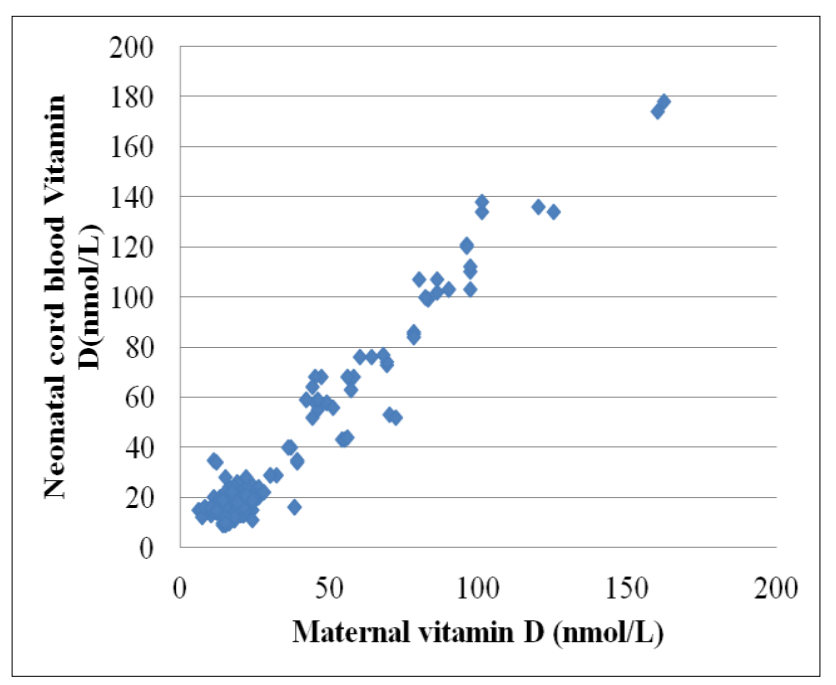

Figure 1: Relationship between maternal and neonatal vitamin D levels.

Figure 1 shows a positive linear relationship between maternal and cord blood vitamin D ( $\mathrm{r}$ 0.974, p 0.0001). As shown in Table 2, maternal ALP levels were higher in 166 patients out of whom 145 had vitamin D deficient levels, 17 had vitamin D insufficient levels and 4 were sufficient in vitamin D. Mean maternal ALP was significantly higher $(114.30 \pm 15.59)$ in vitamin D deficient patients $(\mathrm{p}<0.05)$ and showed a negative correlation $(\mathrm{r}=-0.5503, \mathrm{p}=0.000)$ with maternal vitamin D.

Table 2: Distribution of maternal ALP levels according to maternal vitamin D levels.

\begin{tabular}{|c|c|c|c|}
\hline $\begin{array}{l}\text { Maternal } \\
\text { ALP } \\
\text { (IU/L) }\end{array}$ & $\begin{array}{l}\text { Vitamin D } \\
\text { deficient } \\
(n=156)\end{array}$ & $\begin{array}{l}\text { Vitamin D } \\
\text { insufficient } \\
(n=42)\end{array}$ & $\begin{array}{l}\text { Vitamin D } \\
\text { sufficient } \\
(\mathbf{n}=22)\end{array}$ \\
\hline$<33$ & 0 & 0 & 2 \\
\hline $\begin{array}{l}33-96 \\
\text { (normal } \\
\text { value) }\end{array}$ & 11 & 25 & 16 \\
\hline$>96$ & 145 & 17 & 4 \\
\hline
\end{tabular}

As seen in Table 3, plasma PTH was in the normal range in 216 patients of which 156 were vitamin D deficient, 38 insufficient and 22 had sufficient vitamin D levels. Plasma PTH was significantly higher $(29.75 \pm 6.59)$ in mothers with hypovitaminosis $(\mathrm{p}<0.05)$ and showed a negative correlation $(\mathrm{r}=-2.084, \mathrm{p}=0.000)$ with maternal vitamin D.

Table 4 shows that 175 patients had hypocalcaemia, a majority of which $87.4 \%(153 / 175)$ were vitamin D deficient and 22 had insufficient vitamin D levels. Mean maternal calcium was lowest $(7.91 \pm 0.28)$ in vitamin D deficient patients $(\mathrm{p}<0.05)$ which was statistically significant and showed a positive correlation $(r=0.7486$, $\mathrm{p}=0.000$ ) with maternal vitamin $\mathrm{D}$.

Table 3: Distribution of maternal PTH levels according to maternal vitamin $\mathrm{D}$ levels.

\begin{tabular}{|l|l|l|l|}
\hline $\begin{array}{l}\text { Maternal } \\
\text { PTH } \\
\text { (picogm/ml) }\end{array}$ & $\begin{array}{l}\text { Vitamin D } \\
\text { deficient } \\
(\mathrm{n}=156)\end{array}$ & $\begin{array}{l}\text { Vitamin D } \\
\text { insufficient } \\
(\mathrm{n}=42)\end{array}$ & $\begin{array}{l}\text { Vitamin D } \\
\text { sufficient } \\
(\mathrm{n}=22)\end{array}$ \\
\hline $\begin{array}{l}<15 \\
\begin{array}{l}15-65 \\
\text { (normal } \\
\text { value) }\end{array}\end{array}$ & 0 & 4 & 0 \\
\hline$>65$ & 0 & 38 & 22 \\
\hline Chi square=17.27, $\mathrm{p}=0.000$ & 0 & 0 \\
\hline
\end{tabular}

Table 4: Distribution of maternal calcium levels according to maternal vitamin $\mathrm{D}$ levels.

\begin{tabular}{|l|l|l|l|}
\hline $\begin{array}{l}\text { Maternal } \\
\text { calcium } \\
(\mathbf{m g} / \mathrm{dl})\end{array}$ & $\begin{array}{l}\text { Vitamin D } \\
\text { deficient } \\
(\mathbf{n = 1 5 6})\end{array}$ & $\begin{array}{l}\text { Vitamin D } \\
\text { insufficient } \\
(\mathbf{n = 4 2})\end{array}$ & $\begin{array}{l}\text { Vitamin D } \\
\text { sufficient } \\
(\mathbf{n}=\mathbf{2 2})\end{array}$ \\
\hline $\begin{array}{l}<.5 \\
8.5-10\end{array}$ & 3 & 22 & 0 \\
\hline $\begin{array}{l}\text { (normal } \\
\text { value })\end{array}$ & 20 & 22 \\
\hline$>10$ & 0 & 0 & 0 \\
\hline Chi square $=137.53, \mathrm{p}=0.000$ & \\
\hline
\end{tabular}

Table 5 shows that neonatal cord blood vitamin D levels were significantly lower in pregnant women with hypovitaminosis $(16.98 \pm 4.45)$ compared to those with insufficient or sufficient vitamin D levels $(48 \pm 19.18$ and $115.27 \pm 25.23$ respectively) ( $\mathrm{p}$ value $<0.05$ )

Table 5: Association of maternal vitamin D levels with neonatal vitamin D and neonatal anthropometry.

\begin{tabular}{|c|c|c|c|c|}
\hline & $\begin{array}{l}\text { Vitamin D deficient } \\
(\mathrm{n}=156)\end{array}$ & $\begin{array}{l}\text { Vitamin D insufficient } \\
(\mathrm{n}=\mathbf{4 2})\end{array}$ & $\begin{array}{l}\text { Vitamin D sufficient } \\
(\mathrm{n}=\mathbf{2 2})\end{array}$ & $P$ value \\
\hline Neonatal cord blood vitamin D & $16.98 \pm 4.45$ & $48 \pm 19.18$ & $115.27 \pm 25.23$ & $<0.05$ \\
\hline Neonatal weight & $2878.80 \pm 396.21$ & $2926.90 \pm 375.49$ & $2875.90 \pm 415.34$ & 0.774 \\
\hline Neonatal length & $48.87 \pm 1.06$ & $48.66 \pm 1.16$ & $48.84 \pm 1.45$ & 0.560 \\
\hline Neonatal head circumference & $33.44 \pm 0.82$ & $33.57 \pm 0.89$ & $33.38 \pm 0.46$ & 0.601 \\
\hline
\end{tabular}


Mean weight, length and head circumference of newborns in vitamin $\mathrm{D}$ deficient mothers was $2878.80 \pm 396.21 \mathrm{~g}, \quad 48.87 \pm 1.06 \mathrm{~cm}, \quad 33.44 \pm 0.82 \mathrm{~cm}$ respectively. Mean weight, length and head circumference of new-borns in vitamin $\mathrm{D}$ sufficient mothers was $2875.90 \pm 415.34 \mathrm{~g}, \quad 48.84 \pm 1.45 \mathrm{~cm}$, $33.38 \pm 0.46 \mathrm{~cm}$ respectively. Also, neonatal weight, length and head circumference did not have a significant correlation with maternal levels of vitamin D.

\section{DISCUSSION}

Vitamin D deficiency in Indian population is prevalent to a range of $70-100 \% .{ }^{10}$ Metabolism of calcium, regulation of insulin production, reduction in the risk of diabetes and cancer, rennin production, destruction of infectious agents, regulation of cell growth, enhancing immunity, maintenance of vascular tone of the body, myocardial function is done by vitamin D. ${ }^{11}$ Recently, Vitamin D has received enormous attention worldwide and is referred as the "drug of the decade". Therefore, authors aimed to associate maternal serum vitamin D levels with the neonatal levels.

Present study revealed widespread vitamin D deficiency in expectant subjects and their neonates with $70.91 \%$ expectant women having insufficient to severely deficient vitamin D levels which also reflected in their newborns (71.82\%) and showed a positive linear relationship. Rajoria et al similarly reported that $86 \%$ of women in their study conducted in SMS Medical College Jaipur from June 2014 to April 2015, were deficient, 12.4\% insufficient and only $1.6 \%$ had sufficient vitamin D levels. ${ }^{12}$ Sahu et al observed a higher incidence of decreased vitamin D in expectant subjects (74\%) from rural Indian community in a study conducted in Barabanki, Lucknow. ${ }^{13}$

In the present study, subjects' mean age was reported to be $25.75 \pm 3.36$ years. Deficiency of vitamin $D$ in expectant females in the age group of 19-25 years was found to be significant $(50.45 \%)$.

It is worrisome that $82 / 111(73.87 \%)$ young patients were vitamin D deficient. Dietary inadequacy, low BMI and lower socio-economic status are the probable contributory factors of this observation. Similar results were quoted by Rajoria and they too have found vitamin $\mathrm{D}$ deficiency more in expectant females $<30$ years as compared to those more than 30 years with $\mathrm{p}$ value of $<0.001$. The mean age was found to be 24 years. ${ }^{12}$

In the present study, the mean maternal ALP $(r=-0.5503$, Chi square $=88.38, p=0.000$ ) was significantly higher $(114.30 \pm 15.59)$ in vitamin D deficient patients $(\mathrm{p}<0.05)$ with a weak negative correlation. As depicted in Table 4, maternal serum calcium bears a positive correlation with vitamin $D$ levels which is statistically significant $(\mathrm{r}=0.7486$, Chi square=137.53, $\mathrm{p}=0.000)$. Authors observed high plasma PTH levels with hypovitaminosis which was statistically significant and bears a negative correlation $(r=-2.084$, Chi square $=17.27, \mathrm{p}=0.000)$.

In a study by Sachan et al in Lucknow in 207 women, maternal vitamin $\mathrm{D}$ was less than $10 \mathrm{ng} / \mathrm{mL}$ in $42.5 \%$ (88 patients), whereas in $66.7 \%$ (138 patients), value of $25(\mathrm{OH}) \mathrm{D}$ was less than $15 \mathrm{ng} / \mathrm{mL}$. Plasma PTH values were considerably more $(125 \pm 153 \mathrm{pg} / \mathrm{mL})$ in $42.5 \%(88$ patients) and less $(51 \pm 39 \mathrm{pg} / \mathrm{mL})$ in $66.7 \%(138$ patients) in females with vitamin D levels $<25 \mathrm{nmol} / \mathrm{L}$ ( $\mathrm{p}<0.05) .{ }^{14}$

Maghbooli et al reported an inverse relationship between PTH and serum vitamin D concentrations in subjects $(r=$ -0.18, $\mathrm{P}=0.002$ ). Also, they concluded that vitamin $\mathrm{D}$ concentrations and ALP were related inversely with each other in mothers $(\mathrm{r}=-.265, \mathrm{p}=0.001) .{ }^{15}$

In the present study, mean weight, length and head circumference of newborns in vitamin $\mathrm{D}$ deficient mothers was $2878.80 \pm 396.21 \mathrm{~g}, \quad 48.87 \pm 1.06 \mathrm{~cm}$, $33.44 \pm 0.82 \mathrm{~cm}$ with $\mathrm{p}$ value of $0.774,0.560$ and 0.601 respectively. However, there was no considerable relation among levels of maternal vitamin $\mathrm{D}$ and neonatal anthropometry.

Maternal vitamin D had a positive linear co-relation with cord blood vitamin D. Although anthropometry was not affected, hypovitaminosis D in neonates is an important etiological factor for neonatal hypocalcaemia which can manifest as neonatal seizures as well as bone growth and mineralization in early childhood which can have long term consequences. Its implications are more severe in preterm neonates.

Our results are similar to that of Rajoria et al who reported the mean head circumference, birth weight and length of newborn in vitamin $\mathrm{D}$ deficient mothers to be $33.4 \pm 1.0 \mathrm{~cm}, 2.94 \pm 1.7 \mathrm{~kg}$, and $49.6 \pm 0.9 \mathrm{~cm}$ respectively. They concluded that maternal vitamin D status did not significantly affect neonatal anthropometry. Similar interpretation was made by Maghbooli et al. ${ }^{12}$ No major correlation was found amongst vitamin D concentration in cord blood and concentration of maternal vitamin D and the newborns' characteristics (length, head circumference, weight, diameter of anterior fontanel, diameter of posterior fontanel and APGAR score) and low birth weight. ${ }^{15}$

In contrast to the above observations, Bowyer et al observed that subjects with deficient vitamin $\mathrm{D}$ had a decreased birth weight in newborns. ${ }^{9}$ It could be attributed to the fact that a majority (about 30\%) of growth in the fetal skeleton occurs during the last three months of pregnancy. This growth is related to maternal calcium levels which in turn are dependent on vitamin D levels in mothers. Although, there has been a scattered literature regarding prevalence of vitamin D among pregnant population, but the strength of this study lies in the fact that authors sampled hypovitaminosis $\mathrm{D}$ in 
mothers and their newborns in a population which was not high risk for vitamin D deficiency. However, the limitations were a smaller sample size and shorter duration. Therefore, a follow-up in the infants could not be done for probable adverse outcomes. After this study, authors realize the neglected bone health status of Indian women and the unmet needs of this population. These vitamin $\mathrm{D}$ deficient levels in mothers have translated into low neonatal levels of hormone; thereby affecting their future physical health.

\section{CONCLUSION}

Out of the total 220 patients, $70.91 \%$ had vitamin D deficiency which showed a positive linear relationship with neonatal cord blood vitamin D. No significant correlation was observed between neonatal weight, length, head circumference and maternal vitamin D levels. A weak negative correlation was observed between maternal vitamin D and maternal ALP levels. A positive correlation between maternal vitamin $\mathrm{D}$ and maternal calcium levels was observed. A significant negative correlation between maternal vitamin $\mathrm{D}$ and maternal PTH was observed.

Funding: No funding sources

Conflict of interest: None declared

Ethical approval: The study was approved by the Institutional Ethics Committee

\section{REFERENCES}

1. Gropper SS. Advanced nutrition and human metabolism. 4th ed. ed. Thomson/Wadsworth: Belmont, CA, 2005.

2. Bikle D. Non-classic actions of vitamin D. J Clinic Endocrinol Metabol. 2009;94(1):26-34.

3. Wei SQ, Audibert F, Hidiroglou N, Sarafin K, Julien P, Wu Y, Luo ZC, Fraser WD. Longitudinal vitamin $\mathrm{D}$ status in pregnancy and the risk of pre-eclampsia. BJOG: Int J Obstet Gynaecol. 2012;119(7):832-9.

4. Senti J, Thiele DK, Anderson CM. Maternal vitamin $\mathrm{D}$ status as a critical determinant in gestational diabetes. J Obstet, Gynecol Neonat Nursing. 2012;41(3):328-38.

5. Kalra P, Das V, Agarwal A, Kumar M, Ramesh V, Bhatia E, et al. Effect of vitamin D supplementation during pregnancy on neonatal mineral homeostasis and anthropometry of the newborn and infant. Brit $\mathbf{J}$ Nutrition. 2012;108(6):1052-8.

6. Camargo CA, Ingham $\mathrm{T}$, Wickens $\mathrm{K}$, Thadhani RI, Silvers KM, Epton MJ et al, New Zealand Asthma and Allergy Cohort Study Group. Vitamin D status of newborns in New Zealand. British J Nutrition. 2010;104(7):1051-7.

7. Beck-Nielsen SS, Brock-Jacobsen B, Gram J, Brixen $\mathrm{K}$, Jensen TK. Incidence and prevalence of nutritional and hereditary rickets in southern Denmark. Europ J Endocrinol. 2009;160(3):491-7.

8. McGrath J. Does 'imprinting' with low prenatal vitamin D contribute to the risk of various adult disorders? Medical Hypothes. 2001;56(3):367-71.

9. Bowyer L, Catling-Paull C, Diamond T, Homer C, Davis G, Craig ME. Vitamin D, PTH and calcium levels in pregnant women and their neonates. Clinic Endocrinol. 2009;70(3):372-7.

10. Gupta A. Vitamin D deficiency in India: prevalence, causalities and interventions. Nutri. 2014;6(2):72975.

11. Hossein-nezhad A, Holick MF. Vitamin D for health: a global perspective. In Mayo clinic proceedings 2013;88(7):720-55.

12. Rajoria N, Gupta ML, Rajoria L, Rajoria NB. Study of Association Between Maternal 25-hydroxy Vitamin D3 Level and Neonatal Outcome. Develop. 2015;6(7):8-13.

13. Sahu M, Bhatia V, Aggarwal A, Rawat V, Saxena P, Pandey A et al. Vitamin D deficiency in rural girls and pregnant women despite abundant sunshine in northern India. Clinic Endocrinol. 2009;70(5):680-4.

14. Sachan A, Gupta R, Das V, Agarwal A, Awasthi PK, Bhatia V. High prevalence of vitamin D deficiency among pregnant women and their newborns in northern India. Am J Clinic Nutriti. 2005;81(5):1060-4.

15. Maghbooli Z, Hossein-Nezhad A, Shafaei AR, Karimi F, Madani FS, Larijani B. Vitamin D status in mothers and their newborns in Iran. BMC Pregnancy and Childbirth. 2007;7(1):1.

Cite this article as: Sandhu A, Nautiyal R, Mehrotra V, Wasim S. Effect of hypovitaminosis D and its related factors in pregnant women and their newborns. Int J Reprod Contracept Obstet Gynecol 2019;8:1115-9. 